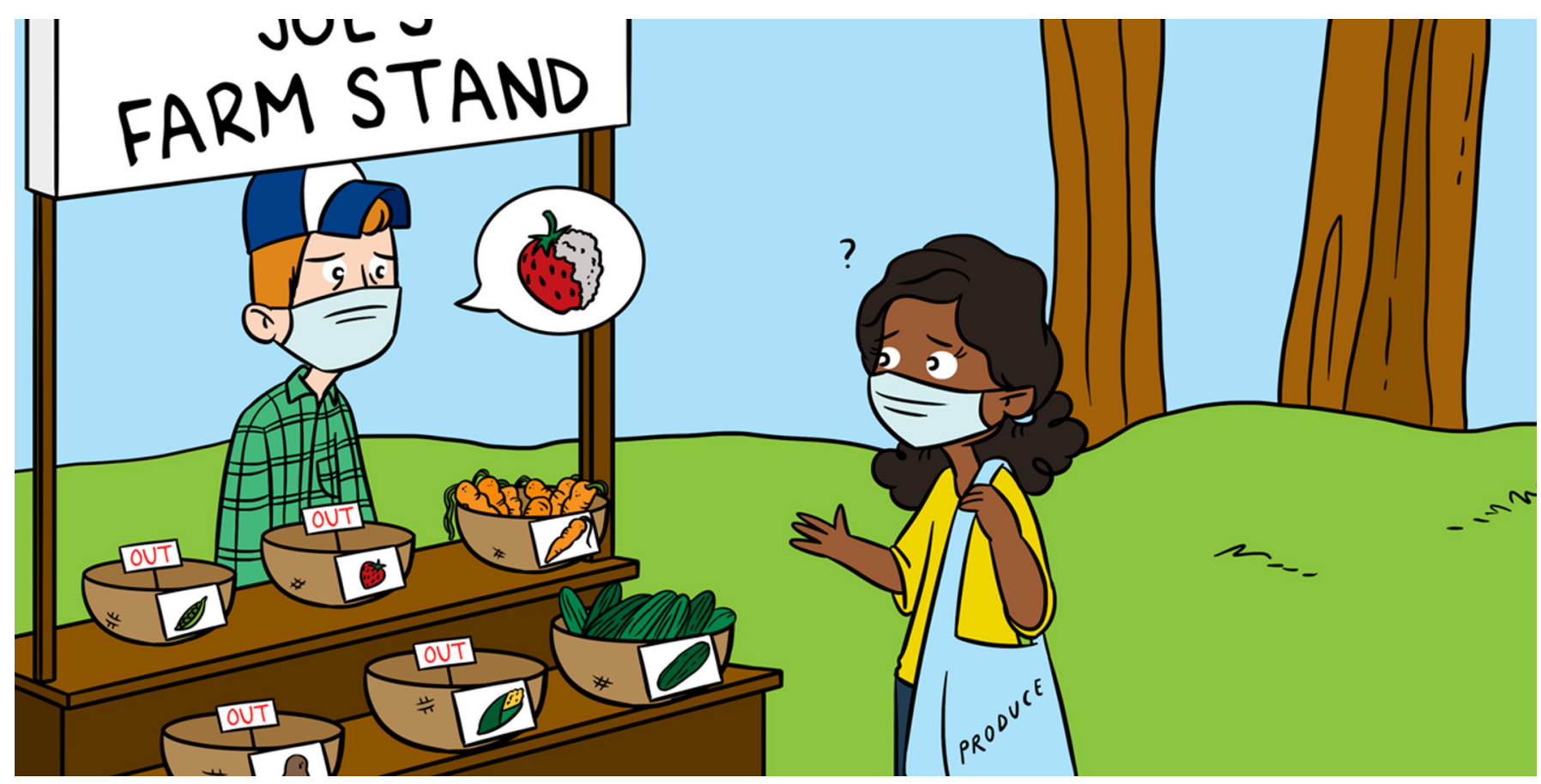

\title{
THE DARK SIDE OF FUNGI: HOW THEY CAUSE DISEASES IN PLANTS
}

\section{Demetrio Marcianò ${ }^{1+}$, Chiara Mizzotti ${ }^{2 *}$, Giuliana Maddalena ${ }^{1}$ and Silvia Laura Toffolatti ${ }^{1 *}$ \\ ${ }^{1}$ Department of Agricultural and Environmental Sciences, University of Milan, Milan, Italy \\ ${ }^{2}$ Department of Biosciences, University of Milan, Milan, Italy}

\section{YOUNG REVIEWERS:}
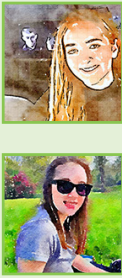

KATIE

AGE: 15

Q RIA

AGE: 15
If you have ever kept fruits, vegetables, or even bread in your kitchen for a long time, you have probably noticed the formation of a grayish and fuzzy covering over them. But what exactly are those grayish-white filaments? Are they dangerous for us? They are living things and they belong to the group of organisms called fungi. These fungi grow on other organisms, using them as a source of nourishment. In this article, we introduce fungi and describe how they can attack plants, fruits, and vegetables.

\section{FUNGI CAN ATTACK PLANTS}

Many of us know fungi as disease-causing organisms or as mushrooms that grow in the lawn or forests. However, these examples are only a few members of the huge groups of fungi, which has many thousands of members. For instance, the yeast, that scientists call Saccharomyces cerevisiae, is a single-celled organism used to make bread and pizza dough rise, or to ferment wine and beer, is a fungus (Figure 1A). We can 
Figure 1

(A) Yeast cells are extremely small single-celled fungi (size $0.003-0.04 \mathrm{~mm}$ ), that mostly reproduce by budding, in which baby cells separate from the mother cell, leaving a visible mark on it (arrow). (B)

Filamentous growth of hyphae. The mushroom structure we are familiar with is called the fruiting body. (C) Mushroom circles, often called fairy rings, can occur in lawns or forests. They are the result of the circular shape of the underground mycelium.

\section{PATHOGEN}

An agent (e.g., virus, bacteria, or fungi) that can cause a disease to a living organism.

FUNGUS (PL. FUNGI)

Group of living organisms that are not animals, plants, or bacteria. Some familiar fungi are mushrooms, molds, mildews, and yeasts. They absorb their food from dead or living organisms, and some of them can cause diseases to plant and animals.

\section{FRUITING BODY}

The part of a fungus in which the spores are produced. Usually, it corresponds to the part of the fungus that we eat.

HYPHA (PL. HYPHAE)

Fine filaments produced by the fungus to grow and feed.

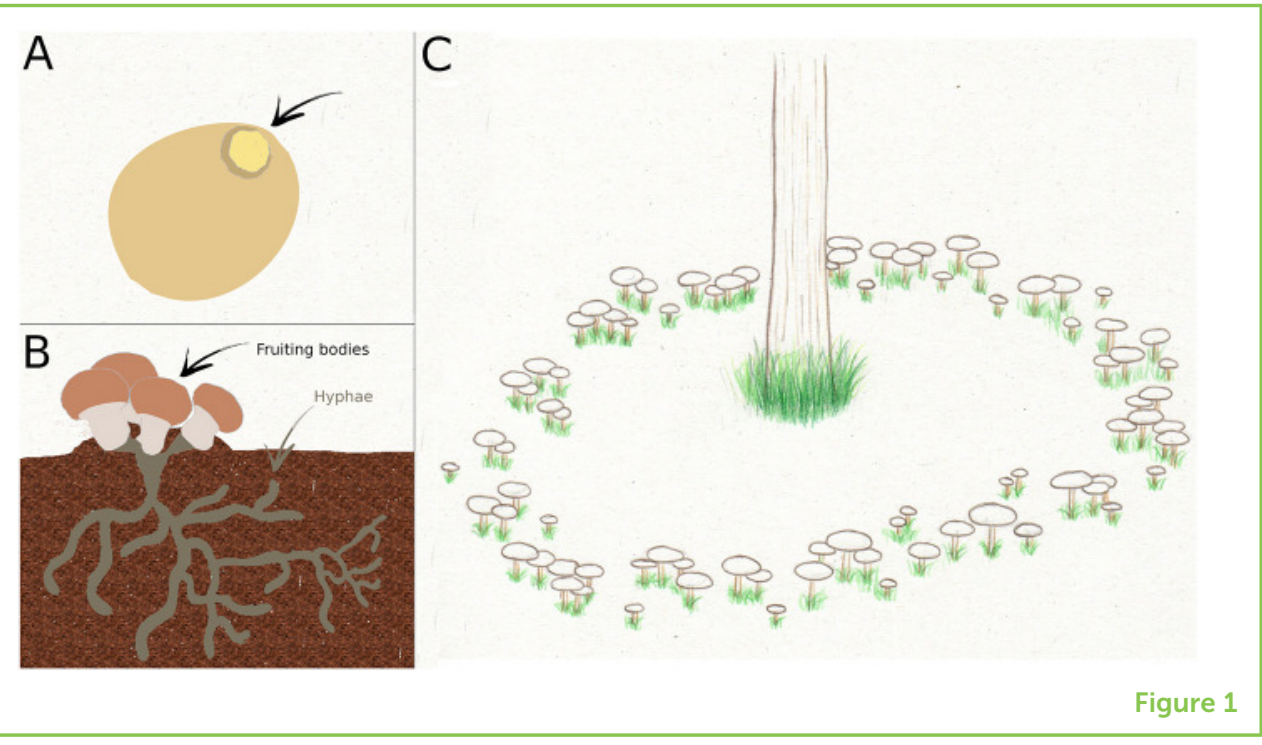

also obtain medicines, such as antibiotics, from certain fungi. These are examples of how fungi can be useful to us.

However, there are also fungi that can attack plants, causing plant diseases. Disease-causing organisms, including fungi, are called pathogens. Pathogens of plants use their plant hosts for food, or for a place to reproduce themselves, causing damage to the plant. Fungal pathogens are extremely dangerous and may cause the loss of crop harvests or, in the most serious cases, the death of the plants. Fungi can also negatively affect the quality of crops, causing an accumulation of toxins within the plants. The toxins produced by some fungi are dangerous for humans and animals.

\section{WHAT IS A FUNGUS?}

When we think about fungi, we usually imagine edible mushrooms like button mushrooms. However, the mushroom structure is only one part of the fungus, called the fruiting body (Figure 1B). Fungi have many different shapes and colors. Most fungi are formed from thread-like filaments called hyphae. Hyphae are the structures that allow fungi to grow and feed, and they can also form specialized structures necessary for the fungus to survive or capture prey. The mushrooms we are used to seeing have hyphae that grow under the ground in large, intricate networks of filaments, called the mycelium. The underground mycelium can sometimes grow in a circular shape, with the fruiting bodies of mushrooms on its edges (Figure 1C).

Fungi reproduce by producing spores, which are kind of like seeds and can form directly on the hypha or on other specialized structures. The familiar fruiting body of a mushroom is formed by some fungi to disperse spores into the environment. From a single spore, the fungus can produce new hyphae that will grow into a new mycelium [1]. The 
MYCELIUM (PL.

MYCELIA)

The main "body" of a fungus, consisting of a network of hyphae.

\section{SPORE}

A structure of reproduction. Spores can survive for a long time in unfavorable conditions.

SCLEROTIUM (PL. SCLEROTIA)

A compact mass of hyphae produced by fungi to survive harsh conditions. The sclerotium gives rise to new fungal growth or spore-producing structures when environmental conditions are right. mycelium could be defined as the real "body" of the fungus, while the spores constitute its offspring.

\section{FUNGAL PLANT PATHOGENS: DEVASTATING ORGANISMS}

When the climate conditions are right, fungal pathogens can grow exponentially and devastate crops. For instance, a fungus called botrytis bunch rot can destroy more than $80 \%$ of strawberry flowers and fruits [2]. The same fungus can also attack tomatoes, affecting up to $70 \%$ of the plants and causing premature death. This fungus can infect more than 1,400 different species of plants, including grapes, raspberries, blackberries, beans, lettuce, and flowers, such as roses, gerbera, daisies, and orchids.

It has been estimated that fungal pathogens cause the loss of hundreds of billions of US dollars across the world every year. Humans can directly suffer the consequences of fungi attacks. For instance, the Great Famine in Ireland (1845-1852), which caused the death of 1 million people, was triggered by a pathogen called potato late blight fungus that destroyed potatoes, the principal source of food for poor people at the time.

\section{THE DISEASE CYCLE OF A FUNGAL PATHOGEN}

Pathogenic fungi can live inside plants or on their surfaces. So, to survive, the fungal life cycle must follow the plant's growing stages. Think about apple trees: in autumn, they lose all their leaves, and in winter they are alive but dormant. A pathogenic fungus living on apple tree leaves must be able to survive until spring, when new leaves are available. In cases like these, pathogenic fungi can produce spores or special hyphae called sclerotia, which are made to resist unfavorable conditions. Other fungi hide inside the plant, waiting for favorable conditions, or move to another host plant that is active during the unfavorable period. Lastly, some fungi survive the winter in the ground, by feeding on dead plant and animal material.

When the host plant becomes available in the spring, the fungus is ready to infect (Figure 2). To reach the plant, the fungus produces spores, which are transported by wind, water, or animals, such as insects. Once on the plant, the spores stick to the surface and the infection begins. Infection consists of two stages: penetration of the host tissues and colonization of those tissues. The fungus must penetrate the host tissues to reach the nutrients inside. The fungus can penetrate through natural openings in the plant, or it can get in through wounds, like insect damage, on the plant's surface. Alternatively, some fungi penetrate by damaging the plant's surface with specialized substances or structures. After penetration, hyphae 
Figure 2

Growth of the pathogenic fungus botrytis bunch rot. (A) The sclerotia, which is the survival structure. $(B, C)$ In spring, sclerotia germinate, producing hyphae with spores at their tips. (D) Spores are released. $(\mathrm{E}-\mathrm{H})$ Spores reach wounded plant tissues or plant organs. (I) Spores germinate, penetrate, and invade tissues, producing hyphae. $(\mathbf{J}, \mathbf{K})$ Fungi damage plant cells and then feed on those plant tissues. (L) When fungi collect enough nutrients they produce new spores, visible as gray mold (N), to repeat the cycle. $(\mathbf{M}-\mathbf{Q})$ Symptoms vary depending on the plant species and organ infected [3].

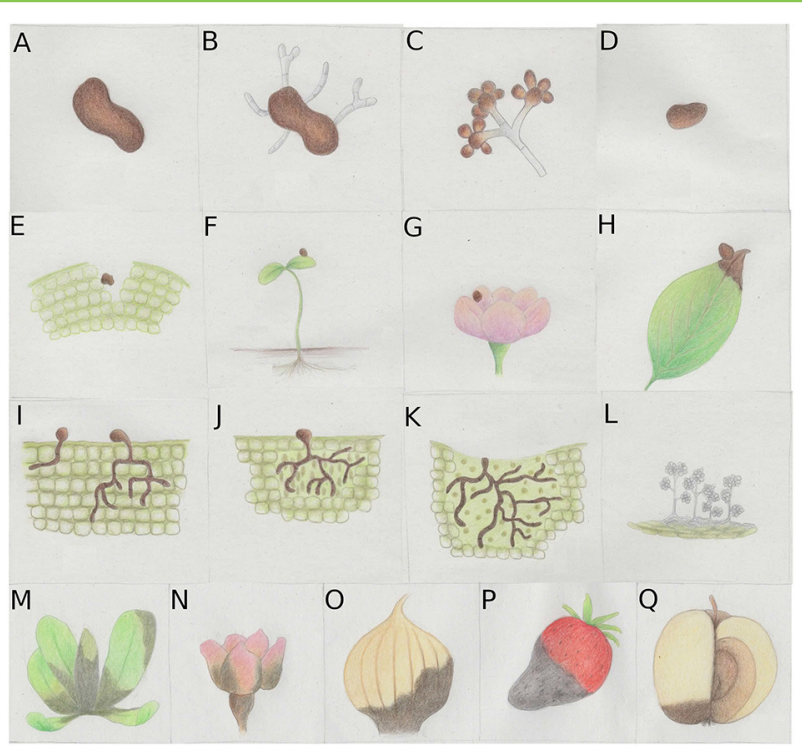

Figure 2

are produced. During colonization, the hyphae grow in the tissues, searching for nutrients. Some fungi immediately kill the plant cells to feed on their nutrients, whereas other types of fungi take up nutrients from living cells through a specialized structure produced from the hyphae.

Some fungal pathogens perform only a single infection cycle in a season, while others perform several cycles in a season, by producing new spores at the end of the colonization process. The number of new infection cycles in the season depends on weather conditions: if the weather is favorable, numerous secondary cycles occur, causing great damage to the plants and crops [4].

\section{COMMON SYMPTOMS OF FUNGAL DISEASES}

Symptoms are the visible effects of a disease caused by a pathogen. Different fungi can attack different plants and plant organs, so fungal infections cause an enormous range of disease symptoms, such as color and shape changes, rotting, wounds, and wilting (Figure 3). Color changes can appear as leaf yellowing and can be accompanied by changes in leaf shape. Cell death causes parts of the plant to decompose and turns plant tissues into a dark color; this can appear as spots on leaves, or rotten spots on fruits. Mildews and molds are not disease symptoms but are the visible parts of the fungus on the plant surface, including the mycelium and spores. Some fungal diseases cause small wounds on plant organs that look like scabs. The disease symptoms help us to figure out which fungal disease is affecting the plant, so that we can apply the right defensive tools to treat the infection. 
Figure 3

Symptoms caused by fungi. Color alterations on grapevine (A-grape downy mildew) and basil (B-basil downy mildew). Shape alterations on peach (C-peach leaf curl). Necrosis on grapevine (D-grape black rot). Fruit rot on an orange (E-rot fungus). Mold on bread (F-black bread mold). Mildew on grapevine (G) and on a weed $(\mathbf{H})$. Botrytis bunch rot on grapevine and strawberry $(\mathbf{I}, \mathbf{J})$ and black mold on grapes (K). Apple scab fungus on apples ( $L$ ) and beech tree dead from dry rot (M), necrosis ( $\mathbf{N}$-grape downy mildew). Wilting on grapevine (O-leaf stripe disease). Dry rot fruiting body $(P)$.

\section{CROP VARIETY}

A specific group of a plant selected by humans for its characteristics (e.g., fruit quality or resistance to diseases).
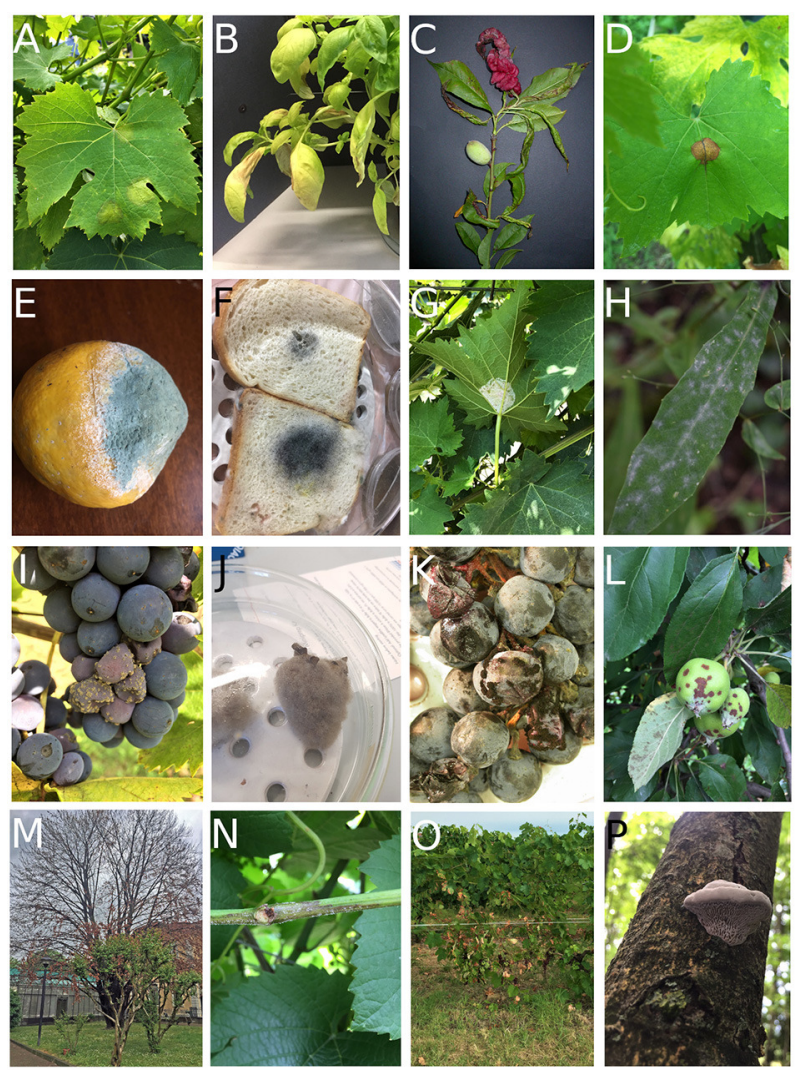

Figure 3

\section{DISEASE CONTROL}

Plants cannot communicate with us, so sometimes it is difficult to understand when they are sick. Furthermore, once we see disease symptoms on plant tissues, it is impossible to heal the plants. We can only reduce the damage by decreasing the spread of the disease to neighboring, healthy organs and plants. This means that prevention is the most effective way to manage plant diseases. To prevent fungal diseases, several methods can be used: the cultivation of fungus-resistant crop varieties, the use of appropriate farming practices, and the use of fungicides, which are chemical substances able to kill fungi.

A resistant crop could have various strategies to overcome fungal attack and development, like stronger physical barriers or the production of anti-fungal compounds [5]. Unfortunately, a resistant crop is only resistant to a limited range of fungal pathogens, and sometimes the fungus can overcome the plant's resistance. However, the proper use of fungus-resistant crops can reduce the issues caused by plant pathogens.

Farming practices aim at reducing the conditions that favor fungal diseases. For example, by quickly removing and destroying diseased plants, or by disinfecting the soil or plant seeds with heat or chemicals, 
farmers can reduce the number of fungi present in the crop's environment. Crop rotation decreases the number of spores in the ground, simply by changing the types of crops grown in the field every year. Watering and fertilization also must be balanced, to avoid excessive production of leaves, which favors the spread of fungal pathogens.

Very often, these measures are not sufficient to provide the complete control of fungal diseases, so farmers must use fungicides to prevent fungal infections [4]. Please remember that fungicides can be used only by experts, under controlled conditions, because the misuse of these products can be harmful to humans, other organisms, and the environment.

\section{PREVENT FUNGI IN YOUR HOME!}

As we said at the beginning of this article, you might sometimes see fungi growing on your food. Some of those fungi might be plant pathogens that were carried on the food surface directly from the field, while others might be fungi present in your home! To keep your foods safe to eat and to prevent food waste, there are some prevention measures you can take in your kitchen. Maintain clean food-storing places to limit the presence of spores, and discard rotted or moldy products quickly, to keep the fungi from spreading. You can also protect food from fungi by avoiding the hot, humid conditions they like-store foods in cool, dry locations as much as possible. You can also pay attention to your houseplants. Check them regularly for disease symptoms and remove leaves with symptoms to avoid disease spreading. If you get rid of a dead plant, it is better to change the soil in the pot, in case fungi or spores are present in the soil. Using these simple practices, we can all protect our foods and help to reduce the number of plant pathogens in our environments!

\section{ACKNOWLEDGMENTS}

We wish to thank Prof. Federico Zerbetto for the peach leaf curl and black mold photographs shown in this article and Dr. Elisa Cadei for drawing the pictures. This project has received funding from the European Union's Horizon 2020-EU.1.2. - FET Open research and innovation action under grant agreement no. 828940.

\section{REFERENCES}

1. Peter, M. 2006. Ectomycorrhizal fungi - fairy rings and the wood-wide web. New Phytol. 171:685-87. doi: 10.1111/j.1469-8137.2006.01856.x

2. Petrasch, S., Knapp, S. J., van Kan, J., and Blanco-Ulate, B. 2019. Grey mould of strawberry, a devastating disease caused by the ubiquitous necrotrophic fungal 
pathogen Botrytis cinerea. Mol. Plant Pathol. 20:877-92. doi: 10.1111/ mpp.12794

3. Guest, D., and Brown, J. 1997. "Plant defences against pathogens," in Plant Pathogens and Plant Diseases, eds J. F.Brown and H. J. Ogle ( Armidale, NSW: Rockvale Publications). p. 263-86.

4. Agrios, G. N. 2005. Plant Pathology, 5th Edn. London: Elsevier Academic Press.

5. Holtz, G., Coertze, S., and Williamson, B. 2004. "The ecology of Botrytis on plant surface," in Botrytis: Biology, Pathology and Control, eds Y. Elad, B. Williamson, P. Tudzynski, and D. N. Kluwer (Dordrecht: Academic Publishers). p. 67-84.

SUBMITTED: 08 May 2020; ACCEPTED: 21 May 2021;

PUBLISHED ONLINE: 25 June 2021.

EDITED BY: Johnathan J. Dalzell, Queen's University Belfast, United Kingdom

CITATION: Marcianò D, Mizzotti C, Maddalena G and Toffolatti SL (2021) The Dark Side of Fungi: How They Cause Diseases in Plants. Front. Young Minds 9:560315. doi: $10.3389 /$ frym.2021.560315

CONFLICT OF INTEREST: The authors declare that the research was conducted in the absence of any commercial or financial relationships that could be construed as a potential conflict of interest.

COPYRIGHT (c) 2021 Marcianò, Mizzotti, Maddalena and Toffolatti. This is an open-access article distributed under the terms of the Creative Commons Attribution License (CC BY). The use, distribution or reproduction in other forums is permitted, provided the original author(s) and the copyright owner(s) are credited and that the original publication in this journal is cited, in accordance with accepted academic practice. No use, distribution or reproduction is permitted which does not comply with these terms.

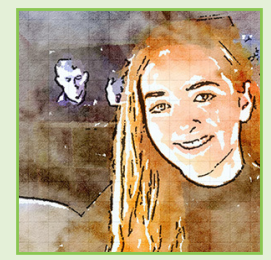

\section{YOUNG REVIEWERS}

\section{ANNA, AGE: 16}

I wanted to do Frontiers for Young Minds because I thought it would be a great opportunity to learn more about the world around me! I love science, particularly biology and physics. After school I would love to do something with those subjects.

\section{KATIE, AGE: 15}

At school I am currently studying Biology, Chemistry, and Geography. I love music and the outdoors and through Frontiers for Young Minds I hope to learn more about people and the world!

\section{RIA, AGE: 15}

I am Ria. I enjoy dancing, reading, listening to music, and hanging out with my friends. I am interested in Frontiers for Young Minds because I would like to pursue a career involving science! 

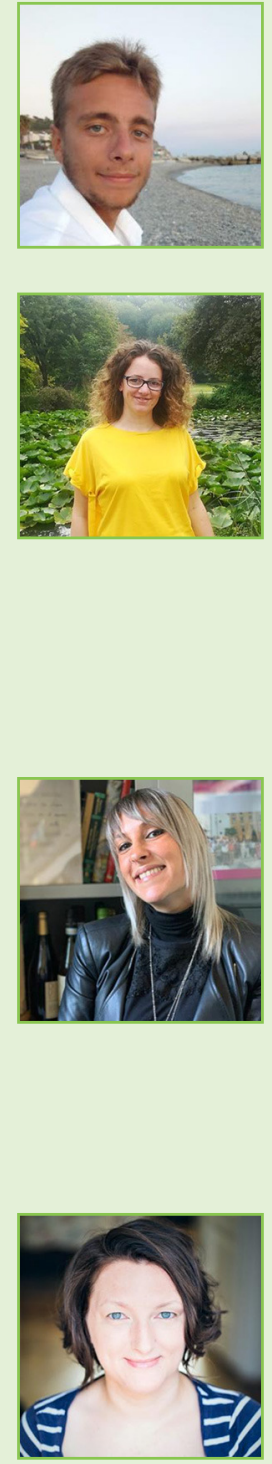

\section{AUTHORS}

\section{DEMETRIO MARCIANÒ}

Since I was a child, I have always been curious and interested in understanding natural phenomena and the world that surrounds me. I have a degree in agricultural sciences, and I am studying pathogenic plant fungi and new ways to fight them.

\section{CHIARA MIZZOTTI}

Chiara Mizzotti graduated in biological sciences and got her Ph.D. in plant biology. She is a technician at the Plant Platform, at the University of Milan, Department of Bioscience. Her work is focused on understanding the molecular mechanisms that control fruit and seed development in different plant species. She hopes to identify new solutions to delay fruit ripening and to prevent fruit losses. She is responsible for teaching people about her laboratory's projects, and this new aspect of her work is becoming more important and interesting every day: making people passionate about science! *chiara.mizzotti@unimi.it

\section{GIULIANA MADDALENA}

Giuliana Maddalena is a post-doc at the University of Milan, Department of Agricultural Sciences. From the very start, she has had great interest in participating in scientific research on the causes of crop diseases. She enjoys being constantly stimulated by the challenges that research brings. An early focus of her career was grapevine diseases caused by fungi, and this work turned her interest into a passion. The focus of her current work is finding alternative strategies of plant protection.

\section{SILVIA LAURA TOFFOLATTI}

Silvia Laura Toffolatti specialized in classical studies in high school, graduated in biological sciences and got her Ph.D. in agricultural ecology. She is assistant professor at the University of Milan, Department of Agricultural Sciences. She teaches plant pathology and supervises numerous students. Her work focuses on fungal diseases of grapevines and their management. She hopes that her work on plant-pathogen interactions, fungal biology, and fungicide use optimization will help increase sustainability in grapevine disease management. *silvia.toffolatti@unimi.it

${ }^{\dagger}$ These authors have contributed equally to this work 